\title{
Mechanical characterization of Raw-Perlite Solid Bricks for use in construction
}

\author{
Lucas Ramiro Burgos (Main and Corresponding Author) \\ Universidad Nacional de Salta (Argentina) \\ Universidad Tecnológica Nacional Facultad Regional Córdoba \\ Maestro M. López esq. Cruz Roja Argentina \\ Ciudad Universitaria - Córdoba Capital CP: 5000, Córdoba (Argentina) \\ lucasburgos@conicet.gov.ar
}

Manuscript Code: 1691

Date of Acceptance/Reception: 23.03.2020/04.10.2019

DOI: $10.7764 /$ RDLC.19.1.170-179

\begin{abstract}
In San Antonio de los Cobres located to the west of Salta, Argentine, the residents resort to the use of Adobe bricks to build their houses. Such masonry is made by the residents themselves using old building techniques whose principal material is clay. At present, this material turns out to be scarce in the region due to the growing demand. On the other hand, in the vicinity of the town, there are mining plants which extract perlite generating wastes of particles smaller than 150 microns. With a high-content of residues (70\% by weight), raw solid bricks are elaborated with a CINVA-Ram compacting unit. The aim of the present research work is to analyze the possibility of replacing Adobe bricks with these new bricks. Such analyses will follow tests which comply with IRAM standards (official national standards body for the Republic of Argentine), such as compression and flexion strength, absorption, capillary absorption and thermal conductivity tests. In conclusion, our results indicated that rawperlite brick studied had better physical properties than the Adobe bricks.
\end{abstract}

Keywords: Compressive strength, mechanical properties, residues, sustainability.

Introduction

This research work is about the mechanical characterization of Raw-Perlite Solid Bricks for possible use in construction, using residues of natural perlite without expanding, taking advantage of the fact that said material is not commercialized and is kept in quarries. The absence of clay makes difficult the elaboration of Adobe bricks and RawPerlite Solid Bricks could be a replace those bricks, making other option for construction.

In addition, Salta has high amount of perlite reserves according to geology study not yet published.

Perlite is a volcanic origin rock formed during explosive eruptions and it is a hydrated volcanic glass formed through the secondary alternative of obsidians by the incorporation of water into the glass silica structure (Jamei et al., 2011).

The total perlite residue turns out to be approximately $20 \%$ of perlite production. On a daily basis, 90 tons of perlite is extracted producing 18 tons of residues each day. Such quantity of perlite favors the production of Raw-Perlite Solid bricks. Each brick needs approximately 3.5 kilograms of residue out of 5 kilograms of its total weight to be fabricated. The remaining weight is compounded by cement, hydrated lime and water.

It was found that mixtures by weight of $70 \%$ Raw-Perlite with $20 \%$ cement and $10 \%$ hydrated lime showed higher compressive strengths using the major percent of residue (Aramayo, Burgos, \& Fernandez, 2016). For higher strength bricks requirements more quantities of cement but it increase the costs. The results showed that addition of perlite waste into brick mixture increased the strength of bricks in late ages. Perlite waste was also used to improve the properties of mixtures by other researchers (El Mir \& Nehme, 2017; Vance et al., 2009).

Published literature contains no information regarding the studies on the production of Raw-Perlite Solid Bricks using perlite as a main raw material in the north of Argentine. This was produced for the first time in the present study.

Theoretical and experimental studies were carried out in the Civil Engineering Laboratory of the National University of Salta, where the CINVA-Ram equipment was placed and the bricks were fabricated. The CINVA-Ram is a simple equipment that it's made up of steel. It's don't require electric energy and with the work of two persons can compact the perlite bricks. These bricks were tested in that same laboratory and in the laboratory on CINTEMAC of the National Technological University - Córdoba Regional Faculty as well. 
To synthesize, the objective is to obtain a brick for construction through the characterization of the raw materials and through the implementation of an adequate experimental design. Then, different results were analyzed so as to compare them and determine which construction material complies with the regulations in force. We here focus our attention in the comparison between raw-perlite bricks with Adobe bricks because the latest are typical of the region of San Antonio de los Cobres.

\section{Problem Statement}

Perlite mining in San Antonio de los Cobres (Figure 1) generates a significant amount of waste, and, because particles are smaller than 150 microns, there is a risk of people involuntary inhaling them. Moreover, clay, which commonly is the raw material for the construction of walls, is becoming scarce.

The general objective is to elaborate perlite bricks using a high volume of natural perlite residues, which can be transferred to the community for their application and, in this way, to contribute to the environmental sustainability.
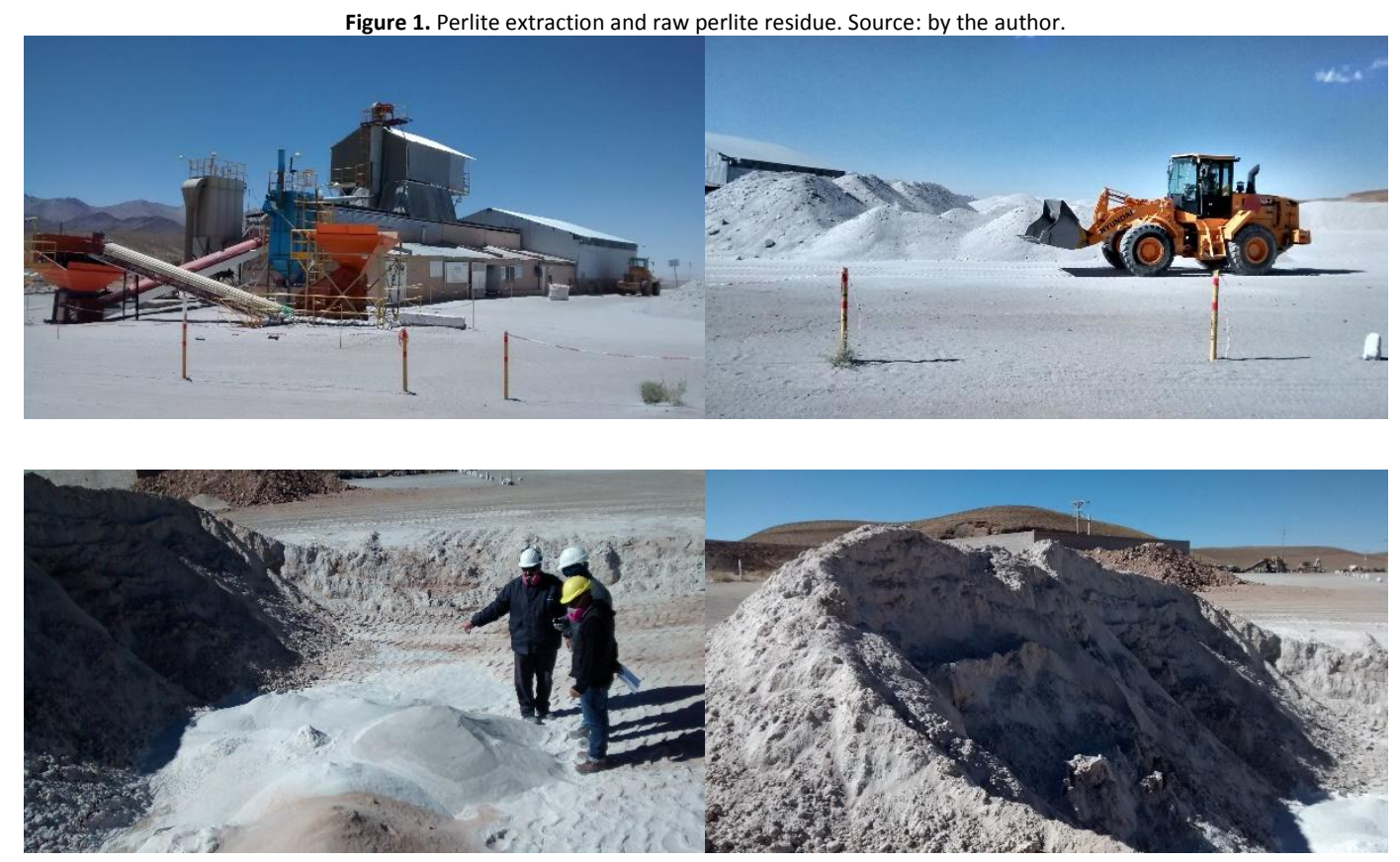

Methodology

\section{Materials}

As said, Perlite is a volcanic origin rock formed during explosive eruptions and it is a hydrated volcanic glass formed through the secondary alternative of obsidians by the incorporation of water into the glass silica structure (Jamei et al., 2011).

Perlite is not a trade name, but a common term for naturally occurring siliceous volcanic rock. The distinguishing feature which arrangements perlite apart from other volcanic glasses is that when rapidly heated to its softening temperature which ranging between $900{ }^{\circ} \mathrm{C}$ to $1200{ }^{\circ} \mathrm{C}$, it expands approximately from 5 to 20 times its original volume(Rashad, 2016).

From a chemical point of view, elevated contents of silicon dioxide (72\%) and alumina (13\%), alkali (sodium and potassium) are prominent, with low levels of iron, calcium and magnesium (Figure 2).

The perlite (75-150 $\mu \mathrm{m}$ of size and $2200-2400 \mathrm{~kg} / \mathrm{m}^{3}$ of real density) used in this study was provided by IMERYS in San Antonio de los Cobres, Salta.

SEM images of the perlite given in Figure 3 indicates that the perlite has an irregular morphology, non-uniform plate shape, glassy form (amorphous structure) and highly porous structure with sharp edges. 

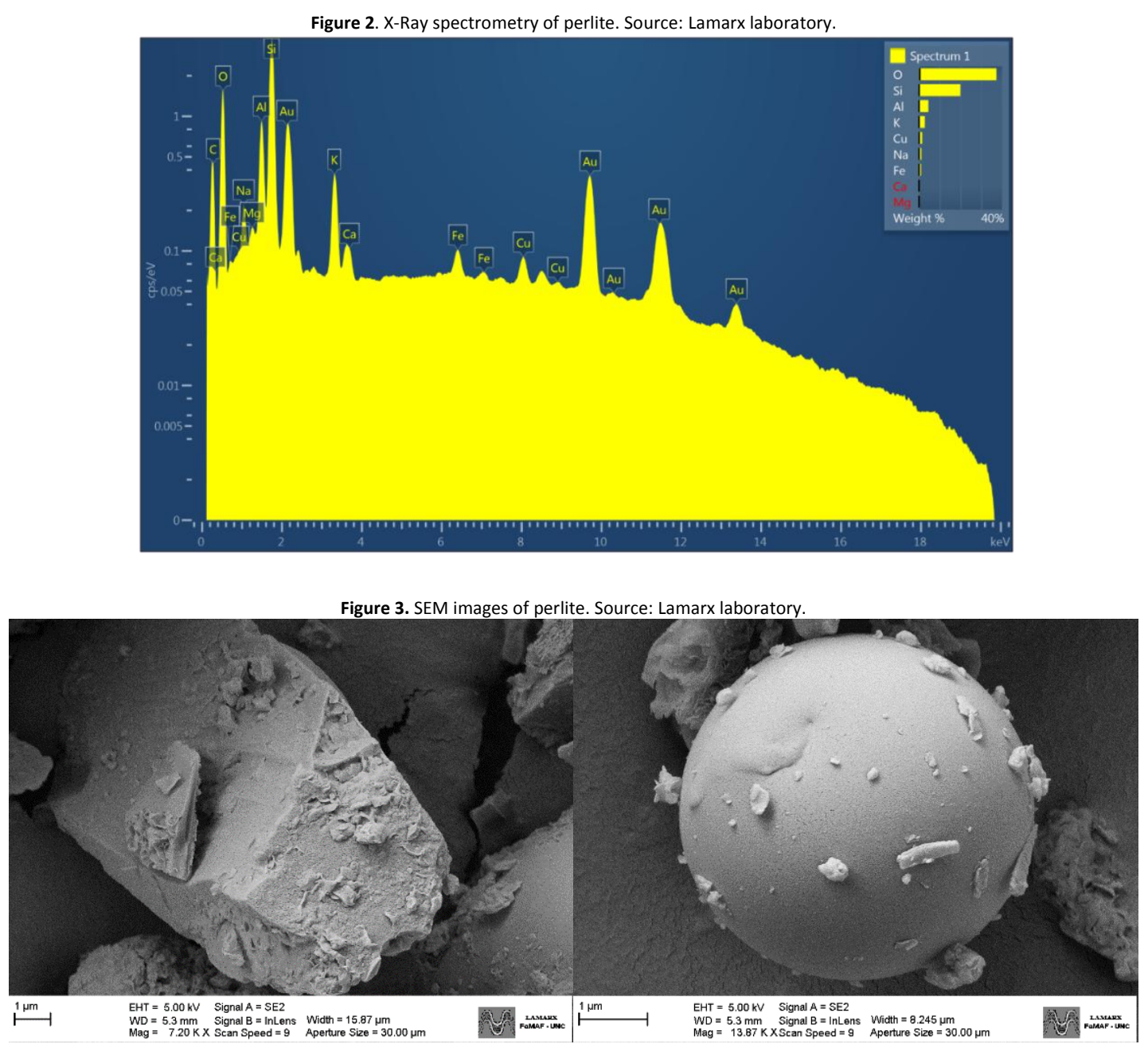

Table 1.Chemical composition of the raw perlite. Source: Lamarx laboratory.

\begin{tabular}{|c|c|c|c|c|c|c|c|}
\hline Element & Line Type & $\begin{array}{c}\text { Apparent } \\
\text { Concentration }\end{array}$ & k Ratio & $\mathrm{Wt} \%$ & $\begin{array}{l}\text { Wt\% } \\
\text { Sigma }\end{array}$ & Standard Label & $\begin{array}{l}\text { Factory } \\
\text { Standard }\end{array}$ \\
\hline 0 & $\mathrm{~K}$ series & 17.63 & 0.05933 & 37.34 & 0.39 & $\mathrm{SiO}_{2}$ & Yes \\
\hline $\mathrm{Na}$ & $\mathrm{K}$ series & 0.73 & 0.00307 & 1.15 & 0.07 & Albite & Yes \\
\hline $\mathrm{Mg}$ & $\mathrm{K}$ series & 0.13 & 0.00089 & 0.22 & 0.04 & $\mathrm{MgO}$ & Yes \\
\hline Al & $\mathrm{K}$ series & 3.37 & 0.02423 & 4.52 & 0.07 & $\mathrm{Al}_{2} \mathrm{O}_{3}$ & Yes \\
\hline $\mathrm{Si}$ & $\mathrm{K}$ series & 15.47 & 0.12255 & 19.91 & 0.11 & $\mathrm{SiO}_{2}$ & Yes \\
\hline K & $\mathrm{K}$ series & 2.40 & 0.02031 & 2.83 & 0.06 & $\mathrm{KBr}$ & Yes \\
\hline $\mathrm{Ca}$ & $\mathrm{K}$ series & 0.29 & 0.00261 & 0.34 & 0.04 & Wollastonite & Yes \\
\hline $\mathrm{Fe}$ & $\mathrm{K}$ series & 0.77 & 0.00768 & 0.95 & 0.09 & $\mathrm{Fe}$ & Yes \\
\hline $\mathrm{Cu}$ & $\mathrm{K}$ series & 1.18 & 0.01182 & 1.51 & 0.14 & $\mathrm{Cu}$ & Yes \\
\hline Total: & & & & 68.76 & & & \\
\hline
\end{tabular}

Cement (CPC30) and hydrated lime were selected for their easy access in the place for which this research is intended. There are common and low cost products.

Adobe is a construction material that present several attractive characteristics. It is low cost, locally available, recyclable, adapted to a large variety of soils, presents goof thermal and acoustic properties, and is associated to simple constructive methods that require reduced energy consumption (Silveira et al., 2012). There are different types of adobes bricks (Austin, 1984), in this case, the adobes bricks in study are traditional.

The techniques adopted in the construction of adobe bricks in San Antonio de los Cobres were based in the accumulated empirical knowledge (Figure 4). 


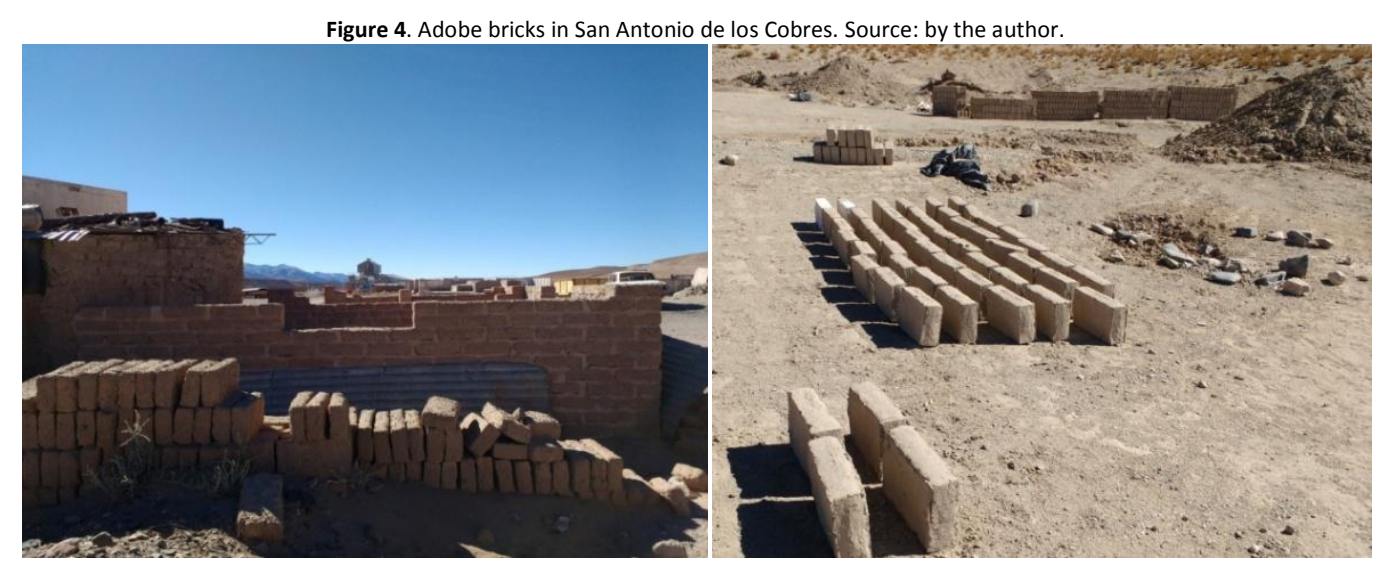

\section{Experimental procedure}

The perlite (70\% by weight), the cement (20\%) and the hydrated lime (10\%) (Aramayo, Burgos, \& Fernandez, 2016), are mixed with a mechanical mixer at determined mixing ratios over a period of $10-15$ min. Water is added to the prepared mixture and the mixture is mixed over a period of 10-15 $\mathrm{min}$. The resulting mixture is poured into the floor and The blocks were molded using hand operated CINVA-Ram machine (Figure5). This mixture which is shaped under 2 bar pressure in the molds is removed and allowed to dry naturally for $24 \mathrm{~h}$. Afterwards, the bricks are kept in a dry room. Curing water is not used due to the scarcity of water in the place for which it is intended. In all the cases the bricks have $0.06 \times 0.20 \times 0.29 \mathrm{~m} 3$ and a density of $1400 \mathrm{~kg} / \mathrm{m}^{3}$.

CINVA-Ram. Description: The CINVA-Ram (Figure 6), which was designed by Raul Ramirez at the Inter-American Housing Center (CINVA) in 1956, is the oldest, truly low-cost, portable soil block press.

The press, made entirely of steel, basically consists of a mould box with a cover, onto which a toggle lever is rolled. This is connected via a yoke to a piston below the mould box, which has a moveable base plate fixed to the piston. When the lever is pressed down, the piston moves upwards between two adjustable angles. The whole unit is mounted on a heavy wooden base board (about $300 \times 20 \times 5 \mathrm{~cm}$ ) to provide stability during operation.

Operating the CINVA-Ram: In the vertical position, the lever arm is fixed to the yoke by means of a latch. These are pulled back together and the mould cover swung open. After greasing the sides of the mould, the mix is filled in, making sure that the corners are properly filled and slightly compressed by hand. When swinging back the mould cover the surplus soil is removed.

The lever is brought back to the vertical position and the latch released. The lever arm is then pulled down on the side opposite to its previous position, to compress the block. When the block is fully compacted, the lever arm is swung back over the mould to its position during filling.

The mould cover is opened and the lever arm depressed further until the brick is completely ejected and held in this position until it is removed from the press and placed on edge at the curing site.

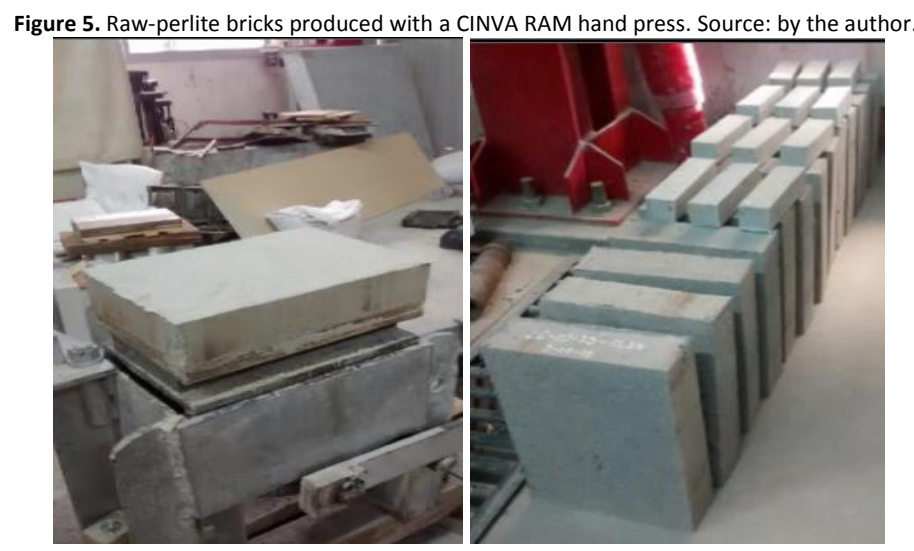




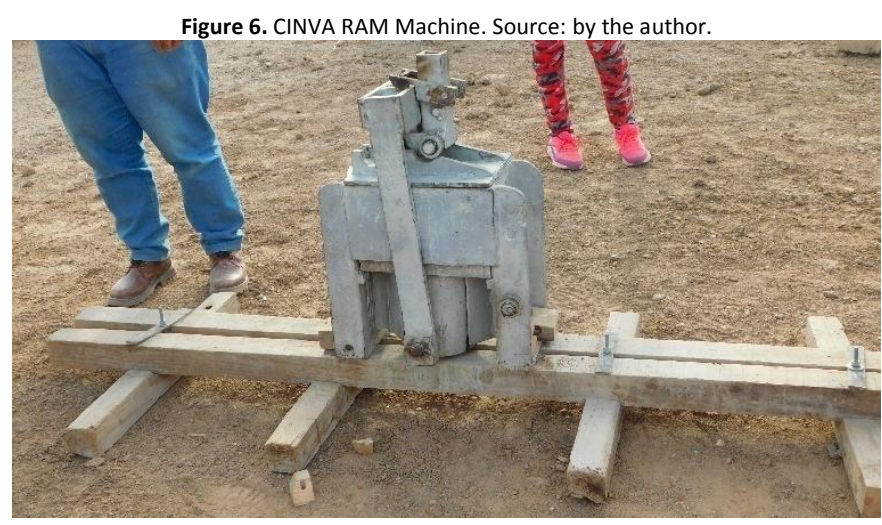

In the next table is indicated the bricks used for determine the mechanical characteristics:

\begin{tabular}{|c|c|c|}
\hline Brick & $\begin{array}{l}\text { Dimensions } \\
{[\mathrm{cm}]}\end{array}$ & Weight [kg] \\
\hline 1 & $20 \times 29 \times 6.3$ & 5.967 \\
\hline 2 & $20 \times 29 \times 6.4$ & 5.991 \\
\hline 3 & $20 \times 29 \times 6.1$ & 5.783 \\
\hline 4 & $20 \times 29 \times 6.6$ & 6.178 \\
\hline 5 & $20 \times 29 \times 6$ & 5.508 \\
\hline 6 & $20 \times 29 \times 6.3$ & 5.836 \\
\hline 7 & $20 \times 29 \times 6.3$ & 5.896 \\
\hline 8 & $20 \times 29 \times 6.5$ & 6.120 \\
\hline 9 & $20 \times 29 \times 6.5$ & 5.608 \\
\hline 10 & $20 \times 29 \times 6.1$ & 5.462 \\
\hline 11 & $20 \times 29 \times 6.3$ & 5.623 \\
\hline 12 & $20 \times 29 \times 6.2$ & 5.492 \\
\hline 13 & $20 \times 29 \times 5.7$ & 4.892 \\
\hline
\end{tabular}

\section{Compressive strength}

According to the IRAM standard 12586 (IRAM 2013a) establishes the testing method for the determination of bricks and ceramic blocks compression strength for the construction of walls, thirteen bricks with 28 days of maturation were tested. By applying the formula of the IRAM standards, the characteristic compression strength value was equal to $3.00 \mathrm{Mpa}$ (Figures 7 and 8). The resistance of the Adobe bricks manufactured in San Antonio de los Cobres, did not exceed $1 \mathrm{MPa}$. Therefore, a previous work elaborated on Adobe bricks tests carried out in the same locality (Sastre, Suarez \& González, 2013) in which the average resistance was equal to $1.33 \mathrm{Mpa}$ was consulted. In other works, the compressive strength is $1.60 \mathrm{MPa}$ in adobe bricks (Lertwattanaruk \& Choksiriwanna, 2011).

In all the cases the value of Perlite bricks is nearly 2 times greater than that Adobe bricks.

The standard deviation and Coefficient of variation had a value of 0.48 and $12.32 \%$ respectively.

\section{Flexion Strength}

According to the IRAM standard 12587 (IRAM 2013b) indicates the guidelines necessary to follow to conduct the flexion test, thirteen bricks with 28 days of maturation were tested. By applying the formula of the IRAM standards, the flexion strength value was equal to $0.78 \mathrm{Mpa}$ (Figures 7 and 8). The tested Adobe bricks presented practically no flexion strength. In other researches indicated that flexion strength in adobe bricks is the $30 \%$ of the compressive strength (Corrêa et al., 2006). In that case, the results of perlite bricks exceed the adobe bricks. 
The standard deviation and Coefficient of variation had a value of 0.18 and $23.70 \%$ respectively.
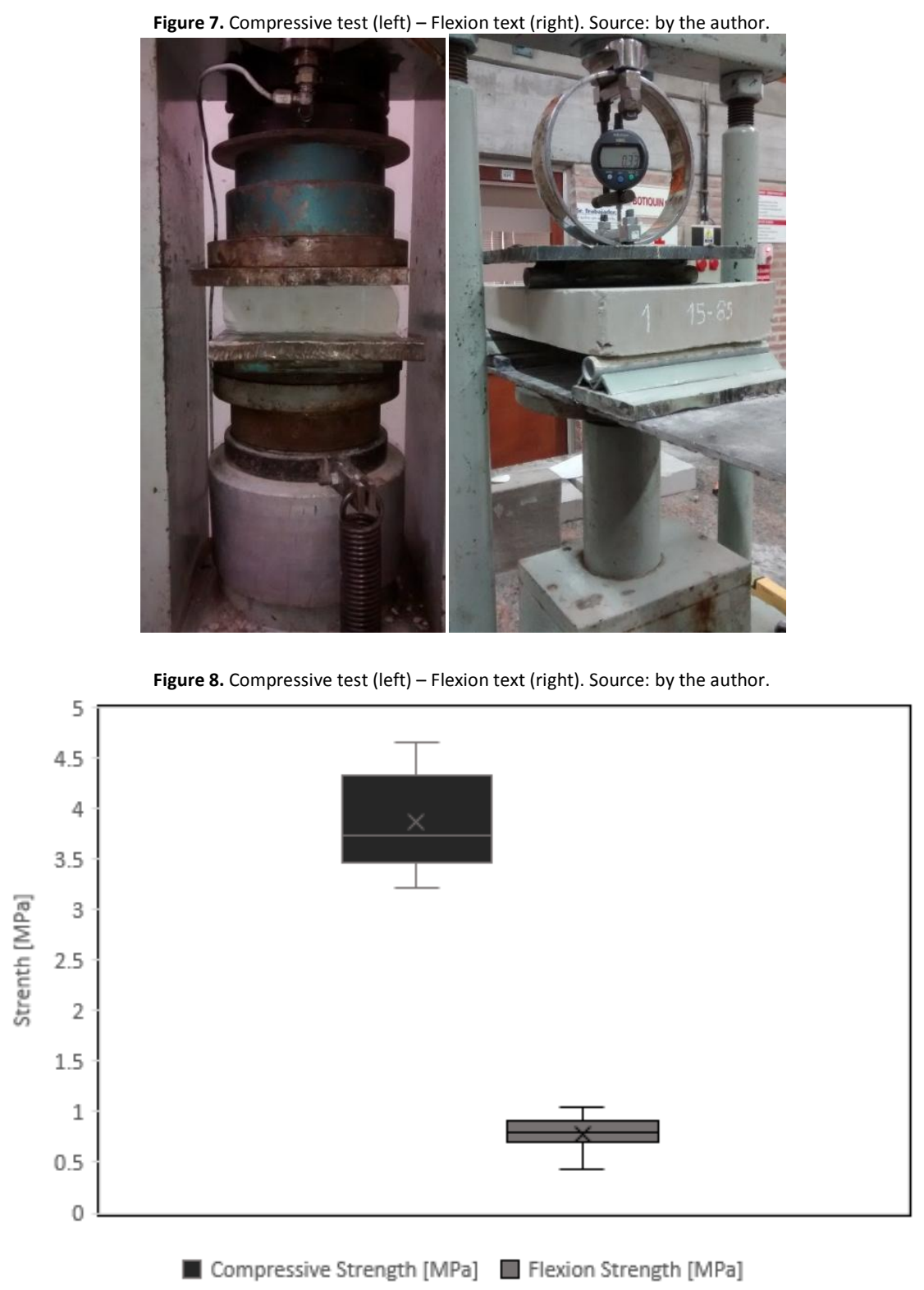

\section{Absorption}

During the absorption test, what is measured is the absorption capacity of the unit submerged in cold water during twenty-four hours. In order to perform the trial, the units are dried, weight and subjected to the aforementioned treatment, after that, the units are weight again. It is called absorption to the difference in weight between the wet unit and the dry unit expressed in percentage of the weight of the dry unit. The consulted standard is the IRAM standard 12588 (IRAM, 2006).

Ten bricks with 28 days of maturation were tested. By applying the formula of the IRAM standards, the characteristic absorption value was equal to $20.14 \%$ (Figure 9). The conventional Adobe brick experienced masonry disintegration during the absorption test which only confirms the high level of vulnerability of the Adobe brick against the action of water. In other research, Adobe bricks had 65-70\% of absorption (Celik et al., 2014; Lertwattanaruk \& Choksiriwanna, 2011), although Perlite bricks has a lower absorption.

The standard deviation and Coefficient of variation had a value of 0.51 and $2.05 \%$ respectively. 


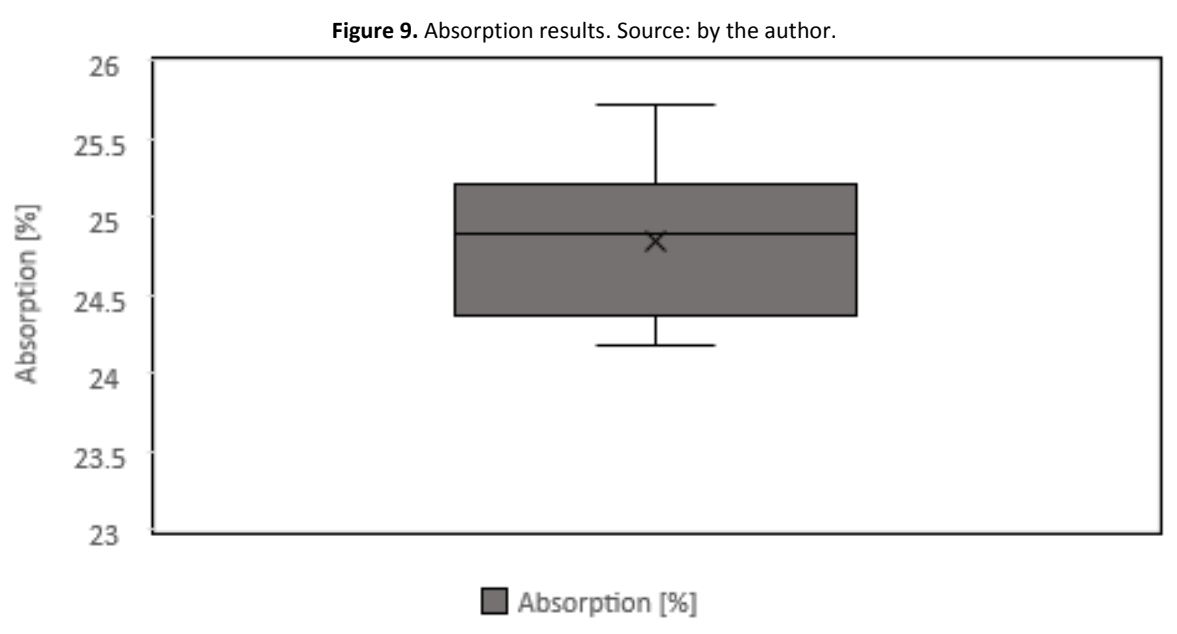

\section{Capillary Absorption}

Absorption is the measurement of the water avidity of the seat face of the masonry and it is a fundamental characteristic to define the mortar-unit relation in the contact interface, and, hence, to define the masonry traction resistance. It is proven that, making use of ordinary building methods, adequate mortar linkages are not attained by using units with an excessive absorption during the settling time. When the absorption is considerably high, the mortar, due to the rapid loss of water which is absorbed by the unit, deforms and hardens, which impedes a full and intimate contact with the face of the following unit. The outcome is a poor and incomplete adhesion resulting in water-permeable unions with low resistance. It is considered that, for absorptions higher than 40 grams per minute in an area of $200 \mathrm{~cm}^{2}$, it is an indispensable requisite of the building process that the units are moisten, following adequate techniques, so as to modify the settling absorption. The consulted standard is the IRAM standard 12586 (IRAM 2013a), which addresses bricks absorption capacity.

Ten bricks with 28 days of maturation were tested. By applying the formula of the IRAM standards, the characteristic capillary absorption value was equal to $0.814 \mathrm{gr} / \mathrm{cm}^{2}$ (Figure 10). The conventional Adobe brick experienced particle release during the absorption test. This impeded the measurement of results and confirms the high level of vulnerability of the Adobe brick against the action of water.

In other research, Adobe bricks had $0.81 \mathrm{gr} / \mathrm{cm}^{2}$ of capillary absorption (Rodríguez \& Saroza, 2006), a similar value compare the perlite bricks.

The standard deviation and Coefficient of variation had a value of 0.08 and $7.97 \%$, respectively.

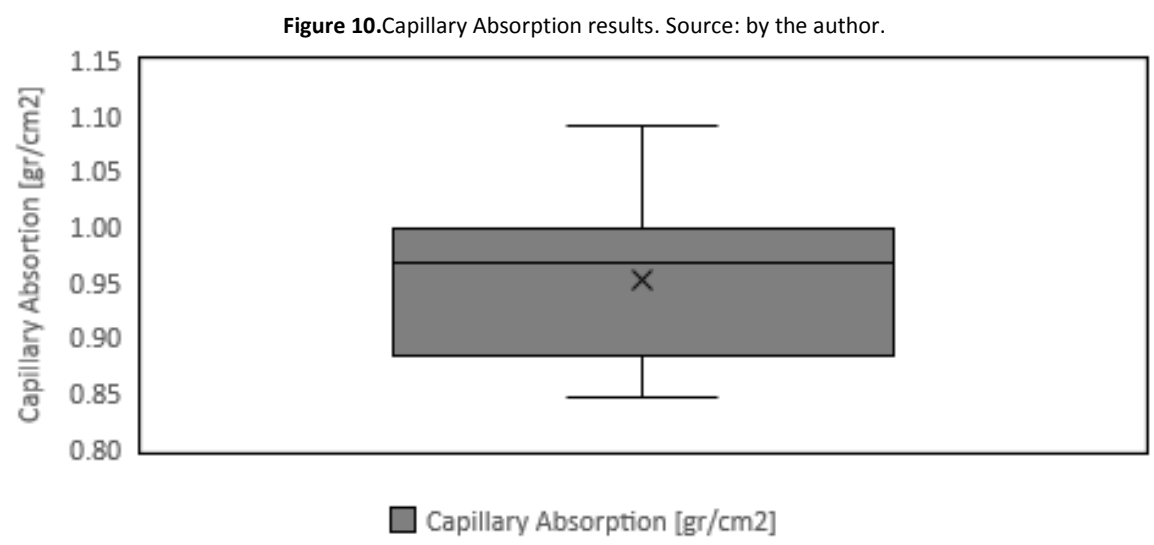

\section{Thermal Conductivity}

The tests on thermal conductivity of the bricks with the chosen dosage were performed in the Materials Engineering and Quality Technology Research Center (CINTEMAC), National Technological University (UTN) - Córdoba Regional Faculty, where a team for the test was provided (Figure 11). The equipment works according to the IRAM standard 11559 (IRAM, 1995). For the test, there were prepared some square plates of $0.30 \times 0.30 \mathrm{~m}$ with a thickness of 
approximately $0.045 \mathrm{~m}$ (Figure 12). Therefore, a mould was elaborated in order to obtain the samples with the needed dimensions. Two layers were filled and 25 impacts per layer were performed, following UTN's recommendations. The aim was that the compaction was similar to that of perlite bricks and, to verify this, the densities of both were compared $\left(1400 \mathrm{~kg} / \mathrm{m}^{3}\right)$.

The thermal conductivity for the tested bricks was equal to 0.76 [W/K.m]. In some researches Adobes bricks have 0.71 [W/K.m] (Lertwattanaruk \& Choksiriwanna, 2011).

Below are some of the thermal conductivity values of the Adobe bricks, analyzed as regards the density by diverse authors (Cuitiño et al., 2015).

\begin{tabular}{cc} 
Table 5. Adobe Bricks Thermal Conductivity. Source: by the author. \\
\hline $\begin{array}{cc}\text { Thermal Conductivity } \\
\text { Density }[\mathrm{kg} / \mathrm{K} / \mathrm{m}]\end{array}$ \\
\hline 750 & 0.20 \\
1200 & 0.46 \\
1650 & 0.82 \\
\hline
\end{tabular}
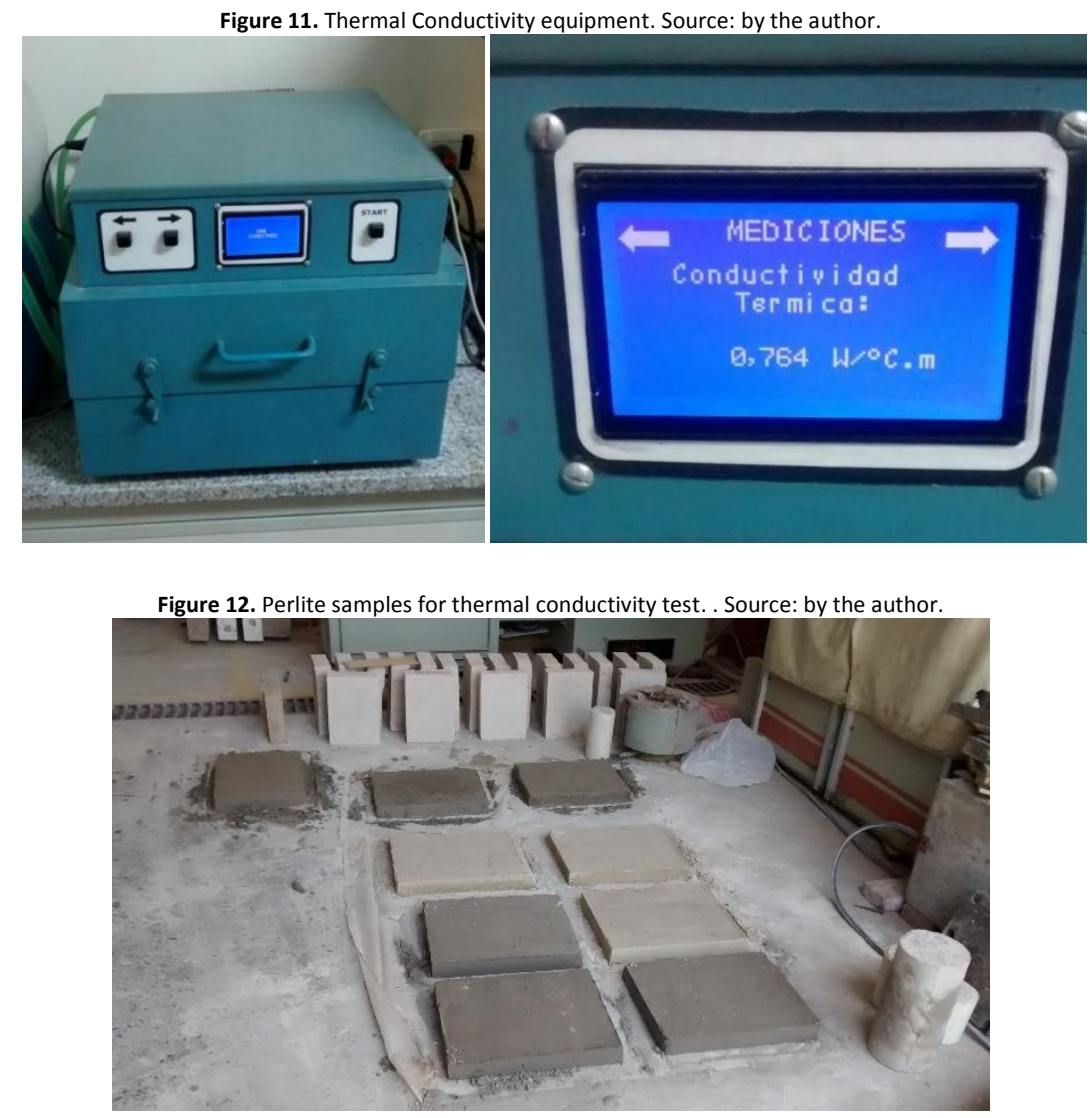

\section{Masonry specimens}

The method to determine the masonry basic compression strength is standardized and consists in stacking the settled units one over the other in a shape of prism.

The slenderness and the minimum height of the prisms depend on whether the units tested are bricks or blocks. In this case, the width/height relation of the prism will be set between 2 and 5 and the height will not be inferior to 35 $\mathrm{cm}$.

The prisms are not treated; they are kept indoors until the moment of the test. These tests are conducted 28 days afterwards, but may also occur sooner than that. 
The test is performed in a universal compression machine by applying a controlled load rhythm until the sample admits no more charges. The result of the test comes from dividing this ultimate charge by the sample area. The test will consist in at least two trials, preferably three.

Four perlite masonry (Figure 13) with 28 days of maturation were tested. According to formula of the IRAM standard 12737 (IRAM, 2005), the compression strength value was equal to $2.78 \mathrm{MPa}, 90 \%$ of unconfined brick strength.

In other research, compressive test results of adobe masonry oscillate 0.88-0.95 Mpa (Wu et al., 2013). The results of the perlite masonry exceed the values of adobe masonry (Figure 14).

Information about the mortar used (Azevedo et al., 2019):

- Mortar application: 1:3 (cement: sand)

- Consistency index (mm): 305

- Axial compressive strength (MPa): $30.4 \pm 0.6$
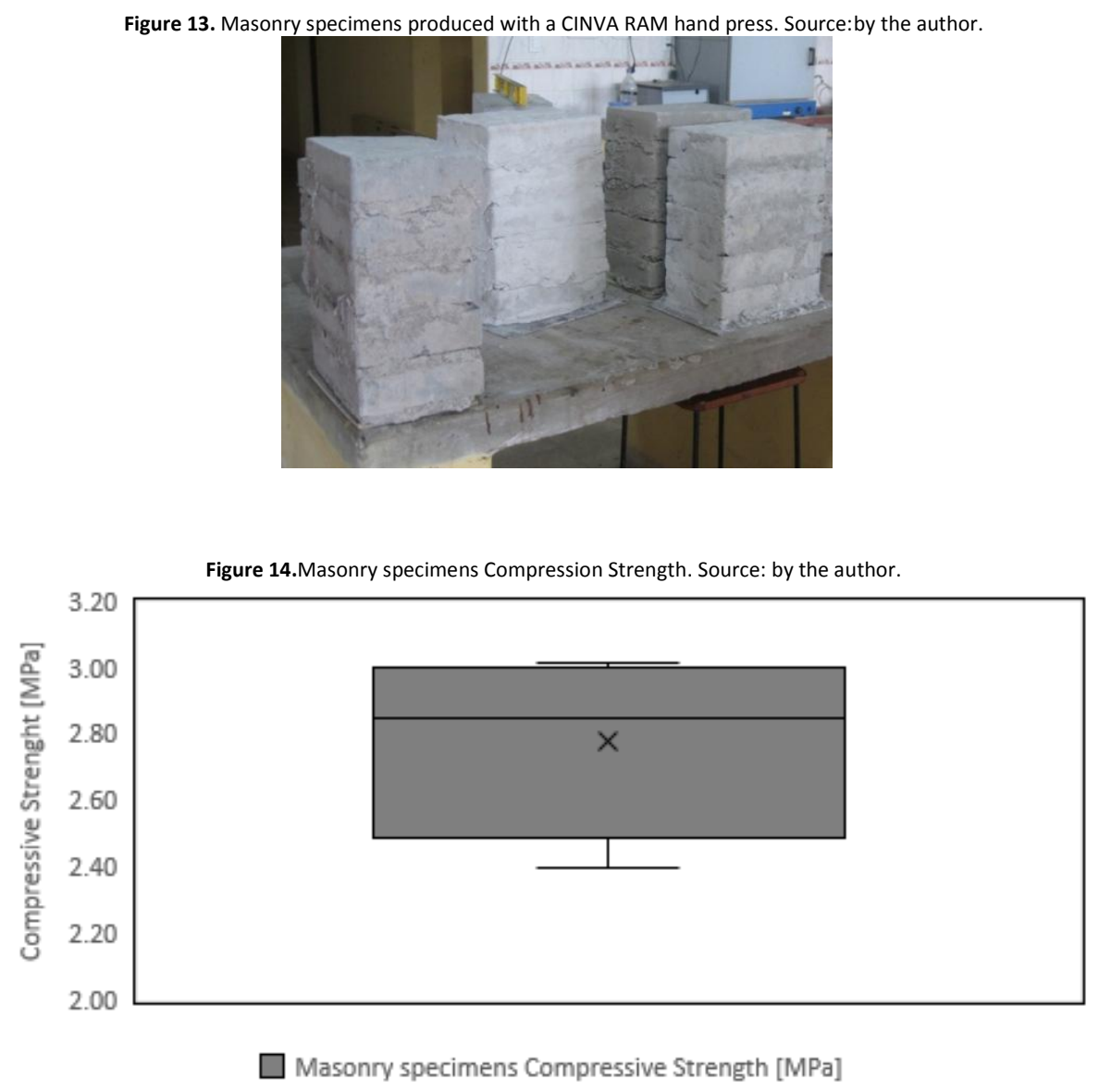

Discussion and Conclusions

In this study, a Raw-Perlite Solid Brick was produced with $70 \%$ by weight of residue perlite. In the production process, the perlite was used as a main material. Characterization studies indicate that the perlite has a glass silica structure. $\mathrm{SiO}_{2}$ and $\mathrm{Al}_{2} \mathrm{O}_{3}$ constitute major content of perlite and $\mathrm{Al}_{2} \mathrm{O}_{3}$ content is higher than $10 \%$ which increase the strength of bricks in late ages.

Compressive strengths, flexion strengths, water absorption, capillary absorption, thermal conductivity and compressive strengths of masonry of the produced bricks were investigated and its physic mechanical properties were compared with adobe bricks. The maximum compressive strength is determined as $3 \mathrm{MPa}$ which is nearly 2 times higher than that adobe brick.

Thermal conductivity $(0.76 \mathrm{~W} / \mathrm{K} . \mathrm{m})$ of the produced bricks are similar than adobe bricks. 
In conclude, these results indicate that the produced perlite bricks have better physical and mechanical properties than the adobe bricks and are promising material for the construction field.

Future research shall include the study of perlite masonry in San Antonio de los Cobres to study effects on properties of perlite bricks.

References

Aramayo, A., Burgos, L., Fernández, M. (2016) Estudio de finos de perlita en la fabricación de ladrillos para su uso en viviendas sociales. Tesis de Grado. Facultad de Ingeniería, Universidad Nacional de Salta, Argentina.

Austin, G. S. (1984). Adobe as aBuilding Material. New Mexico Geology. p. 69-71. https://geoinfo.nmt.edu/publications/periodicals/nmg/6/n4/nmg_v6_n4_p69.pdf

Azevedo, A., Delgado, J. Q., Guimarães, A., Silva, F. A., \& Oliveira, R. (2019). Compression behaviour of clay bricks prisms, wallets and walls - Coating influence. Revista de La Construccion,18(1), 123-133. https://doi.org/10.7764/RDLC.18.1.123

Celik, A. G., Depci, T., \& Kilic, A. M. (2014). New lightweight colemanite-added perlite brick and comparison of its physicomechanical properties with other commercial lightweight materials. Construction and Building Materials. https://doi.org/10.1016/j.conbuildmat.2014.03.031

Corrêa, A. A. R., Teixeira, V. H., Lopes, S. P., \& Oliveira, M. S. de. (2006). Avaliação das propriedades físicas e mecânicas do adobe (tijolo de terra crua). Ciência e Agrotecnologia. https://doi.org/10.1590/s1413-70542006000300017

Cuitiño, G., Esteves, A., Maldonado, G., \& Rotondaro, R. (2015). Análisis de la transmitancia térmica y resistencia al impacto de los muros de quincha. Informes de La Construccion. https://doi.org/10.3989/ic.12.082

El Mir, A., \& Nehme, S. G. (2017). Utilization of industrial waste perlite powder in self-compacting concrete. Journal of Cleaner Production. https://doi.org/10.1016/j.jclepro.2017.04.103

IRAM (2013a). IRAM 12586. Bricks and ceramic blocks for the construction of walls. Compressive strength test method. Buenos Aires: IRAM.

IRAM (2013b). IRAM 12587. Bricks and ceramic blocks for walls. Methods for determining physical characteristics. Flexural test. Buenos Aires: IRAM.

IRAM (2006). IRAM 12588. Bricks and ceramic blocks for the construction of walls. Test method for determining the absorption capacity of water by immersion in cold water and boiling water. Buenos Aires: IRAM.

IRAM (2005). IRAM 12737. Brick masonry and ceramic blocks. Method for determining the compressive strength of walls by testing masonry piles. Buenos Aires: IRAM.

IRAM (1995). IRAM 11559. Thermal conditioning. Determination of thermal resistance and related properties in steady state. Guard hot plate method. Buenos Aires: IRAM.

Jamei, M., Guiras, H., Chtourou, Y., Kallel, A., Romero, E., \& Georgopoulos, I. (2011). Water retention properties of perlite as a material with crushable soft particles. Engineering Geology. https://doi.org/10.1016/j.enggeo.2011.06.005

Lertwattanaruk, P., \& Choksiriwanna, J. (2011). The physical and thermal properties of adobe brick containing bagasse for earth construction. Built. https://doi.org/10.14456/built.2011.5

Rashad, A. M. (2016). A synopsis about perlite as building material - A best practice guide for Civil Engineer. Construction and Building Materials. https://doi.org/10.1016/j.conbuildmat.2016.06.001

Rodríguez, M. A., \& Saroza, B. (2006). Determination of the optimum composition of adobe brick for a school in Cuba. Materiales de Construcción, $56,(282)$.

Silveira, D., Varum, H., Costa, A., Martins, T., Pereira, H., \& Almeida, J. (2012). Mechanical properties of adobe bricks in ancient constructions. Construction and Building Materials. https://doi.org/10.1016/j.conbuildmat.2011.08.046

Vance, E. R., Perera, D. S., Imperia, P., Cassidy, D. J., Davis, J., \& Gourley, J. T. (2009). Perlite waste as a precursor for geopolymer formation. Journal of the Australian Ceramic Society, 45(1), 44-49.

Wu, F., Li, G., Li, H. N., \& Jia, J. Q. (2013). Strength and stress-strain characteristics of traditional adobe block and masonry. Materials and Structures/Materiaux et Constructions. https://doi.org/10.1617/s11527-012-9987-y 